\title{
Sperm viability, reactive oxygen species, and DNA fragmentation index combined can discriminate between above- and below-average fertility bulls
}

\author{
A. Kumaresan, ${ }^{1}$ Anders Johannisson, Essraa M. Al-Essawe, ${ }^{2}$ and Jane M. Morre $I^{3}$ \\ Department of Clinical Sciences, Division of Reproduction, Swedish University of Agricultural Sciences, SE-750 07 Uppsala, Sweden
}

\begin{abstract}
The accurate prediction of bull fertility is of major economic importance in the dairy breeding industry. Sperm fertilizing potential is determined by their ability to reach the oocyte, complete fertilization, and sustain embryogenesis, which is partly determined by the quality of sperm DNA. In the present study, we analyzed several sperm functions required for fertility, including DNA damage, in frozen-thawed spermatozoa of breeding bulls with different adjusted nonreturn rates (NRR56), and identified a suitable combination of parameters that could be used to predict bull fertility. Based on the NRR56, bulls were classified into belowand above-average fertility, a total of 37 characteristics of spermatozoa were evaluated for each bull, and their relationship with bull fertility was studied. Of the different sperm functional attributes, differences were observed in sperm viability, acrosomal integrity, reactive oxygen species, and DNA fragmentation index (\%DFI) among below-average, average, and above-average fertility bulls. Principal component analysis also revealed that sperm viability, acrosome status, reactive oxygen species, and \%DFI were the important variables, having highest correlation with NRR56. Our results indicated that the proportion of live [correlation coefficient $(\mathrm{r})=$ $0.53]$ and live acrosome-reacted spermatozoa $(\mathrm{r}=0.50)$ were significantly positively related to NRR56, whereas the proportion of dead spermatozoa $(\mathrm{r}=-0.53)$ and \%DFI $(\mathrm{r}=0.61)$ were significantly negatively related to NRR56 in bulls. Linear regression analysis indicated that a combination of live [coefficient of determination $\left.\left(\mathrm{R}^{2}\right)=0.72\right]$, dead $\left(\mathrm{R}^{2}=0.72\right)$, live hydrogen peroxidenegative spermatozoa $\left(\mathrm{R}^{2}=0.64\right)$, and \%DFI $\left(\mathrm{R}^{2}=\right.$
\end{abstract}

Received December 19, 2016.

Accepted March 12, 2017.

${ }^{1}$ Current address: Theriogenology Laboratory, Animal Reproduction, Gynaecology and Obstetrics, National Dairy Research Institute, Karnal 132001 Haryana, India.

${ }^{2}$ Current address: Clinical Reproductive Physiology, Al-Nahrain University, High Institute of Infertility Diagnosis and Assisted Reproductive Technologies, Baghdad, Iraq.

${ }^{3}$ Corresponding author: jane.morrell@slu.se
0.56) could differentiate below-average and aboveaverage fertility bulls, and thus were considered for development of a fertility prediction model. The accuracy of the developed model for fertility prediction in bulls was high $\left(\mathrm{R}^{2}=0.83\right)$. We concluded that flow cytometric detection of sperm viability, hydrogen peroxide status, and \%DFI could discriminate below- from above-average fertility bulls.

Key words: dairy bull, sperm attributes, flow cytometry, fertility prediction

\section{INTRODUCTION}

The sustainability and economics of bovine husbandry depends on obtaining high conception rates through AI. The success of AI and optimal use of genetically superior bulls is determined by the fertility of the bull, which in turn depends on sperm quality in frozen-semen doses. Bull fertility is defined as the ability of sperm to fertilize the egg and to sustain embryonic development, which is usually measured by the number of animals sired by a specific bull relative to the number of inseminations performed. Ideally, before induction into the breeding program, a bull is subjected to breeding soundness evaluation (BSE) that involves evaluation of health, libido, mating ability, and routine semen analysis parameters, including volume, sperm concentration, motility, viability, and morphology (Correa et al., 1997). However, this conventional semen analysis has limited value because it is based on a fundamental axiom that an ejaculate must contain above a certain number of motile, morphologically normal spermatozoa to achieve minimum sperm numbers reaching the oviduct to fertilize the oocyte (Rodríguez-Martinez, 2013). The inadequacy of the current semen evaluation method in discriminating high- from low-fertile bulls is evident from the fact that the field fertility of the bulls that have passed through BSE differed among themselves by 20 to 25\% (Larson and Miller, 2000; Aslam et al., 2014).

The most accurate method for testing the bull fertility is insemination of many fertile females (Amann, 2005), but this method is time-consuming, expensive 
for routine use, and allows only a limited number of bulls to be tested at any given time. Thus, researchers and commercial AI companies continuously strive to develop alternative methods to predict bull fertility so that producers can capitalize on desired genetics to improve their herd using frozen semen (Parisi et al., 2014). Several researchers reported that sperm motility (Correa et al., 1997; Rodríguez-Martinez, 2013), velocity parameters (Januskauskas et al., 2003; Nagy et al., 2015), viability and membrane integrity (Christensen et al., 2005, 2011), morphology (Söderquist et al., 1991; Nagy et al., 2013), capacitation status (Bailey et al., 1994; Thundathil et al., 1999), acrosome reaction status (Grippo et al., 1995; Kumaresan et al., 2016), chromatin integrity (Januskauskas et al., 2003), and lipid peroxidation status (Singh et al., 2016) were related to bull fertility. However, the results of such tests do not always correlate with field outcomes (Sudano et al., 2011), because most studies assess a limited number of sperm functions. Prediction of fertilizing ability, therefore, is still largely inaccurate, owing to the fact that fertility is governed by several functions of spermatozoa. Considering the complexity of events involved in the fertilization process, it is unlikely that a single sperm characteristic may reflect the real fertilization capacity of a semen sample (Oliveira et al., 2012). Hence, the fertility potential of a bull can be better estimated when a combination of in vitro sperm assays is performed. Tests for estimation of bull fertility should consider evaluating the spermatozoa for their ability to reach the oocyte, to activate the oocyte, and to sustain embryonic development. However, several earlier studies have primarily focused on the traits necessary for spermatozoa to reach and fertilize the oocyte, ignoring other traits that are essential for oocyte activation and to support early embryonic development (Silva and Gadella 2006). For instance, fertilization of an oocyte by a spermatozoon with DNA damage may jeopardize embryonic development, as the oocyte can only correct a certain degree of DNA damage (Johnson et al., 2011). Furthermore, damaged sperm DNA may be incorporated into the genome of the embryo and lead to errors in DNA replication, transcription, or translation during embryo development, ultimately contributing to diseases in future generations (Katari et al., 2009). In human patients, growing evidence indicates that DNA damage is higher in the spermatozoa of infertile men compared with fertile men (Evenson et al., 1999; Zini et al., 2001; Lewis, 2013), and estimation of sperm DNA integrity may be helpful in unexplained infertility because significant DNA fragmentation can also be present in normozoospermic subfertile men (Erenpreiss et al., 2008; Oleszczuk et al., 2011).
In breeding bulls, infertility can readily be identified using BSE; what is not known, however, is how to identify below-average fertility among fertile bulls. These low-performing bulls can be identified only after largescale use of semen samples for AI and subsequent feedback from the field, which hampers genetic progress. The aim of the present study was to analyze several sperm functions required for fertility, including DNA damage, in frozen-thawed spermatozoa of 20 breeding bulls with different adjusted nonreturn rates (NRR) to identify a suitable combination of parameters that could be used to discriminate above-average fertility bulls from below-average fertility bulls.

\section{MATERIALS AND METHODS}

\section{Source of Semen}

Frozen semen straws prepared from breeding bulls ( $\mathrm{n}=20 ; 14$ Swedish Red and 6 Holstein) with different fertility ratings were procured from Viking Genetics (Skara, Sweden). The collection and freezing of the semen was performed using standard procedures. In brief, the semen was extended with either OptiXcell (IMV, l'Aigle, France) or Andromed (Minitüb GmbH, Tiefenbach Germany), packed into 0.25 -mL plastic straws containing $15 \times 10^{6}$ spermatozoa per straw, frozen, and stored in liquid nitrogen until used.

The relative fertility of the bulls was calculated based on the 56-d NRR. Briefly, the NRR was adjusted for nongenetic parameters, including herd-year-season of insemination, month of insemination, breed of the dam, lactation number, inseminator, and insemination number. The estimates for the random bull effect were used to calculate the relative fertility for each bull. The adjusted NRR for the bulls used in the experiment ranged from 87 to 106 (Table 1 ).

For classification of the bulls into above- and belowaverage, the mean adjusted NRR and standard deviation (SD) was calculated. The bulls having adjusted NRR more than mean +1 SD were classified into the above-average fertility group $(\mathrm{n}=6)$. The bulls having adjusted NRR less than mean -1 SD were classified into the below-average fertility group $(\mathrm{n}=5)$, whereas the rest (mean $\pm 1 \mathrm{SD})$ were classified as average fertility $(\mathrm{n}=9)$.

\section{Sperm Preparation}

Frozen semen straws were thawed at $37^{\circ} \mathrm{C}$ for $12 \mathrm{~s}$. Sperm concentration was measured using a Nucleocounter SP-100 (ChemoMetec, Allerød, Denmark). Briefly, $50 \mu \mathrm{L}$ of the frozen-thawed semen sample was 
mixed with $5 \mathrm{~mL}$ of reagent $\mathrm{S} 100$ (ChemoMetec) and loaded into a cassette containing propidium iodide. The resulting fluorescence was detected and the total number of spermatozoa in the given samples was calculated. For each assay, except for sperm kinematics, 2 million spermatozoa in PBS (Thermo Scientific, Rockford, IL) were used. All the assays were performed immediately after thawing except for the estimation of free thiols, disulfide, protamine deficiency, and DNA fragmentation index (\%DFI); for the latter, the sperm samples were added to TNE buffer $(0.01 \mathrm{~mol} / \mathrm{L}$ of Tris-HCl, $0.15 \mathrm{~mol} / \mathrm{L}$ of $\mathrm{NaCl}$, and $1 \mathrm{mmol} / \mathrm{L}$ of EDTA, $\mathrm{pH} 7.4$ ) $1: 1(\mathrm{vol} / \mathrm{vol})$ at 2 million spermatozoa $/ \mathrm{mL}$ and stored at $-80^{\circ} \mathrm{C}$ until analysis.

\section{Estimation of Sperm Functional Attributes}

Assessment of Sperm Kinematics. Sperm kinematics were analyzed in frozen-thawed semen samples of all the experimental bulls using the SpermVision version 3.5 (Minitüb GmbH) connected to an Olympus BX 51 microscope (Olympus, Tokyo, Japan) fitted with a heated stage $\left(38^{\circ} \mathrm{C}\right)$. Evaluations were made using has a $20 \times$ objective and a $10 \times$ eyepiece; the camera operated at 60 frames per second. An aliquot $(5 \mu \mathrm{L})$ of the sperm sample was placed on a warm glass slide on the microscope stage at $38^{\circ} \mathrm{C}$. Sperm motility was analyzed in 8 fields (at least 1,000 spermatozoa) using the software program on the SpermVision, with settings adjusted for bull spermatozoa. Particles with an area ranging from 20 to $100 \mu \mathrm{m}^{2}$ were included in the analysis. Sperm were identified as immotile (average orientation change $<5$; beat cross frequency $<0.2 \mathrm{~Hz}$; straight line velocity $<0.2 \mu \mathrm{m} / \mathrm{s}$ ), locally motile (straight line distance $<4.5 \mu \mathrm{m}$ ), hypermotile (curvilinear velocity $>80 \mu \mathrm{m} / \mathrm{s}$; linearity $<0.65$; amplitude of lateral head deviation $>6.5 \mu \mathrm{m}$ ), curvilinear (average path distance/radius $>3$, linearity $<0.5$ ) or progressively motile (straightness $>0.5$ and linearity $>0.35$ ). The sperm kinematic parameters estimated included total and progressive motility $(\%)$, average path distance $(\mu \mathrm{m})$, curvilinear distance $(\mu \mathrm{m})$, straight line distance $(\mu \mathrm{m})$, average path velocity (VAP; $\mu \mathrm{m} / \mathrm{s})$, curvilinear velocity (VCL; $\mu \mathrm{m} / \mathrm{s}$ ), straight line velocity (VSL; $\mu \mathrm{m} / \mathrm{s}$ ), straightness (VSL/VAP), linearity (VSL/VCL), wobble (VAP/ $\mathrm{VCL})$, amplitude of lateral head deviation $(\mu \mathrm{m})$, and beat cross frequency $(\mathrm{Hz})$.

Estimation of Sperm Viability. Sperm viability was estimated using SYBR-14 and propidium iodide (PI; LIVE/DEAD Sperm Viability Kit, Molecular Probes, Eugene, OR) according to the procedure described by Goodla et al. (2014), with modifications. The stock solution of SYBR-14 $(1 \mathrm{mM})$ was diluted 50 times; working solution was prepared freshly each day. We added $1.2 \mu \mathrm{L}$ of diluted SYBR-14 and $3 \mu \mathrm{L}$ PI $(2.4$ $\mathrm{m} M)$ to $300 \mu \mathrm{L}$ of PBS containing 2 million spermatozoa and incubated at $37^{\circ} \mathrm{C}$ for 10 min under dark condition before analysis using flow cytometry (FACSVerse, BD Biosciences, Franklin Lakes, NJ). Excitation was induced by a blue laser (488 nm). Green fluorescence was detected with a fluorescence channel (FL) 1 bandpass filter $(527 / 32 \mathrm{~nm})$, and red fluorescence was mea-

Table 1. Fertility details of the bulls used in the experiment

\begin{tabular}{lclcl}
\hline $\begin{array}{l}\text { Bull } \\
\text { no. }\end{array}$ & $\begin{array}{c}\text { Number of } \\
\text { inseminations }\end{array}$ & $\begin{array}{l}\text { Extender } \\
\text { used }\end{array}$ & $\begin{array}{c}\text { 56-d adjusted } \\
\text { nonreturn rate }\end{array}$ & $\begin{array}{l}\text { Classification } \\
\text { of fertility }\end{array}$ \\
\hline 1 & 1,039 & Andromed & 87 & Below average \\
2 & 10,818 & Andromed & 92 & Below average \\
3 & 21,941 & OptiXcell & 92 & Below average \\
4 & 1,726 & OptiXcell & 94 & Below average \\
5 & 248 & OptiXcell & 94 & Below average \\
6 & 381 & OptiXcell & 95 & Average \\
7 & 1,418 & OptiXcell & 96 & Average \\
8 & 1,034 & OptiXcell & 96 & Average \\
9 & 553 & OptiXcell & 97 & Average \\
10 & 42 & OptiXcell & 98 & Average \\
11 & 518 & OptiXcell & 98 & Average \\
12 & 1,284 & Andromed & 100 & Average \\
13 & 109 & OptiXcell & 100 & Average \\
14 & 624 & Andromed & 102 & Average \\
15 & 4,165 & Andromed & 103 & Above average \\
16 & 4,707 & OptiXcell & 103 & Above average \\
17 & 5,814 & Andromed & 104 & Above average \\
18 & 6,072 & OptiXcell & 104 & Above average \\
19 & 6,625 & OptiXcell & 104 & Above average \\
20 & 6,997 & OptiXcell & 106 & Above average \\
\hline
\end{tabular}

${ }^{1}$ OptiXcell (IMV, l'Aigle, France) or Andromed (Minitüb GmbH, Tiefenbach, Germany). 
sured using a FL3 band-pass filter $(700 / 54 \mathrm{~nm})$. A total of 30,000 events were evaluated for each sample. After gating to identify spermatozoa, the cells were classified, according to the degree of intactness of the plasma membrane, as living (SYBR14-positive/PI-negative), dead (SYBR14-negative/PI-positive), and moribund (SYBR14-positive/PI-positive).

Assessment of Acrosomal Reaction Status. Acrosome reaction status of spermatozoa was assessed using fluorescein isothiocyanate-peanut agglutinin (Sigma-Aldrich, St. Louis, MO) as per the procedure given by Kumaresan et al., (2016), with minor modifications. We added $3 \mu \mathrm{L}$ of fluorescein isothiocyanate-peanut agglutinin and $3 \mu \mathrm{L}$ of PI $(2.4 \mathrm{mM})$ to $300 \mu \mathrm{L}$ of PBS containing 2 million spermatozoa and $5 \mu \mathrm{L}$ of Hoechst $33342(50 \mu \mathrm{g} / \mathrm{ml}$; Invitrogen $)$, and the mixture was incubated at $37^{\circ} \mathrm{C}$ for $10 \mathrm{~min}$ under dark conditions. The samples were analyzed using a flow cytometer (FACSVerse, BD Biosciences) with the same parameters as for viability, with the addition that Hoechst 33342 fluorescence (FL5) was excited with a violet 405-nm laser and collected using a 528/45-nm band-pass filter. In total, 30,000 events were evaluated for each sample. After gating to identify spermatozoa, 4 types of population were discerned; live acrosome intact (LAI), live acrosome reacted (LAR), dead acrosome intact (DAI), and dead acrosome reacted (DAR).

Estimation of Mitochondrial Membrane Potential. Mitochondrial membrane potential (MMP) of sperm cells was measured using the lipophilic cationic probe JC-1 (Cossarizza et al., 1993), according to the method described by Goodla et al. (2014). We added $2 \mu \mathrm{L}$ of $3 \mathrm{~m} M 5,5^{\prime}, 6,6^{\prime}$-tetrachloro-1,1',3,3'-tetraethylbe nzimidazolylcarbocyanine iodide (JC-1; Molecular Probes) to $300 \mu \mathrm{L}$ of PBS containing 2 million spermatozoa, and incubated at $37^{\circ} \mathrm{C}$ for 30 min under dark conditions. The samples were analyzed using a flow cytometer (FACSVerse, BD Biosciences). Excitation of stained cells was obtained with a blue laser $(488 \mathrm{~nm})$. Emitted fluorescence was detected using both FL1 $(527 / 32 \mathrm{~nm})$ and FL2 (586/42 nm) filters. Compensation values were $80 \%$ for FL2-FL1 and $0.5 \%$ for FL1FL2. A total of 30,000 cells were evaluated and, after gating to identify spermatozoa, classified in 2 distinct groups: sperm cells with high MMP (orange fluorescence) and those with low MMP (green fluorescence).

Detection of Reactive Oxygen Species. Sperm reactive oxygen species [ROS; superoxide $(\mathbf{S O}), \mathrm{H}_{2} \mathrm{O}_{2}$ ] were measured using the procedure given by Goodla et al. (2014), with minor modifications. Briefly, spermatozoa ( 2 million in $300 \mu \mathrm{L}$ of PBS) were stained with $9 \mu \mathrm{L}$ of $40 \mu M$ Hoechst 33258 (HO; Sigma, Stockholm, Sweden), $9 \mu \mathrm{L}$ of $40 \mu M$ hydroethidine (HE; Invitrogen,
Carlsbad, CA), and $9 \mu \mathrm{L}$ of $2 \mathrm{mM} 2^{\prime}, 7^{\prime}$-dichlorodihydrofluorescein diacetate (Invitrogen) for $30 \mathrm{~min}$ at $37^{\circ} \mathrm{C}$ under dark conditions before analysis in flow cytometer (FACSVerse, BD Biosciences). Excitation was with a blue laser $(488 \mathrm{~nm})$ and a violet laser $(405 \mathrm{~nm})$. Detection of green fluorescence was with a FL1 band-pass filter $(527 / 32 \mathrm{~nm})$, red fluorescence was measured using a FL3 band-pass filter $(700 / 54 \mathrm{~nm})$, and green fluorescence excited by the violet laser was detected with a FL5 band-pass filter $(528 / 45 \mathrm{~nm})$. In total, 30,000 sperm-specific events were evaluated and calculated as percentages. After gating to identify spermatozoa, the spermatozoa detected were classified as live, SO-negative; live, SO-positive; dead, SO-positive; live, $\mathrm{H}_{2} \mathrm{O}_{2^{-}}$ negative; live, $\mathrm{H}_{2} \mathrm{O}_{2}$-positive; dead, $\mathrm{H}_{2} \mathrm{O}_{2}$-negative; and dead, $\mathrm{H}_{2} \mathrm{O}_{2}$-positive by region statistics. Percentages of the total population of sperm-specific events in these regions were calculated.

Simultaneous Measurement of MitochondriaSpecific ROS and MMP. Mitochondria-specific reactive oxygen species (mROS) and MMP were simultaneously estimated in spermatozoa using mitochondria-specific superoxide fluorescent probe MitoSOX Red (MitoSOX) and JC-1 dual-staining method. We added $1 \mu \mathrm{L}$ of MitoSOX Red $(500 \mu M)$ and $1.5 \mu \mathrm{L}$ of JC-1 $(0.9 \mathrm{mM})$ to 2 million spermatozoa in $300 \mu \mathrm{L}$ of PBS and $9 \mu \mathrm{L}$ of $40 \mu M$ Hoechst 33258 (Sigma), and incubated for $30 \mathrm{~min}$ at $37^{\circ} \mathrm{C}$ under dark conditions. The samples were analyzed using a flow cytometer (FACSVerse, BD Biosciences). Excitation was with a blue laser $(488 \mathrm{~nm})$ and a violet laser $(405 \mathrm{~nm})$. Detection of green fluorescence was with a FL1 band-pass filter $(527 / 32 \mathrm{~nm})$, orange fluorescence (FL2) with a 586/42 band-pass filter, red fluorescence with a FL3 band-pass filter $(700 / 54 \mathrm{~nm})$, and blue fluorescence with a FL5 band-pass filter $(528 / 45 \mathrm{~nm})$. A minimum of 30,000 events were evaluated for each sample. After gating to identify spermatozoa, the spermatozoa were classified into 4 types as MitoSOX-positive, JC-1-negative; MitoSOX-positive, JC-1-positive; MitoSOX-negative, JC-1-negative; and MitoSOX-negative, JC-1-positive. Percentages of spermatozoa representing each category were calculated.

Sperm Chromatin Structure Assay. Sperm chromatin structure assay was performed as per the method given by Evenson and Jost (2000), with modifications. Briefly, spermatozoa stored in TNE buffer was were thawed on ice, $100 \mu \mathrm{L}$ of sperm suspension was taken, and $200 \mu \mathrm{L}$ of Triton X-100 (Sigma-Aldrich) detergent solution (0.08 N HCl, $0.1 \%$ Triton $\mathrm{X}-100 ; \mathrm{pH} 1.2)$ was added. After incubation at room temperature for $30 \mathrm{~s}$, the spermatozoa were stained with $600 \mu \mathrm{L}$ of Acridine Orange (AO; Sigma-Aldrich) staining solution (200 
$\mathrm{mmol} / \mathrm{L}$ of $\mathrm{Na}_{2} \mathrm{HPO}_{4} ; 0.1 \mathrm{~mol} / \mathrm{L}$ of citric acid buffer, $\mathrm{pH} 6.0 ; 1 \mathrm{mmol} / \mathrm{L}$ of EDTA; $150 \mathrm{mmol} / \mathrm{L}$ of $\mathrm{NaCl}$; and $6 \mu \mathrm{g} / \mathrm{mL}$ of $\mathrm{AO})$. Within 3 to $5 \mathrm{~min}$ after the addition of $\mathrm{AO}$, the samples were analyzed using a flow cytometer (FACSVerse, BD Biosciences). For each sample, a minimum of 10,000 events were analyzed at a speed of 200 cells/s. Forward scatter (FSC), side scatter (SSC), FL1 (green fluorescence), and FL3 (red fluorescence) were measured after excitation with a blue laser (488 $\mathrm{nm}$ ). The \%DFI [ratio of the percentage of cells with denatured, single-stranded DNA to total cells acquired (both with stable, double-stranded DNA, and denatured single-stranded DNA)] was calculated for each sample using FCS Express version 5 (Denovo Software, Thornhill, ON, Canada).

Protamine Deficiency Assay. Protamine deficiency in spermatozoa was evaluated using Chromomycin A3 (CMA3; Sigma-Aldrich) staining as per the method given by Zubkova et al. (2005), with modifications. Frozen-thawed spermatozoa diluted in TNE buffer (2 million $/ \mathrm{mL}$ ) were washed with PBS by centrifugation $(300 \times g, 10 \mathrm{~min}$ at room temperature, approximately $\left.23^{\circ} \mathrm{C}\right)$. To the washed spermatozoa, $100 \mu \mathrm{L}$ of CMA3 staining solution was added, prepared by dissolving CMA3 (Sigma-Aldrich) in McIlvaine's buffer $[0.2 M$ sodium phosphate dibasic anhydrous $\left(\mathrm{Na}_{2} \mathrm{HPO}_{4}\right) ; 17$ $\mathrm{mL}$ of $0.1 \mathrm{~mol} / \mathrm{L}$ citric acid mixed with $83 \mathrm{~mL}$ of 0.2 $\mathrm{mol} / \mathrm{L} \mathrm{Na}_{2} \mathrm{HPO}_{4}$ and $\left.10 \mathrm{mmol} / \mathrm{L} \mathrm{MgCl}_{2}, \mathrm{pH} 7.0\right]$ to a concentration of $0.25 \mathrm{mg} / \mathrm{mL}$. The spermatozoa were incubated with CMA3 staining solution for $20 \mathrm{~min}$ in the dark, washed in PBS by centrifugation $(300 \times g, 10$ min at room temperature, approximately $23^{\circ} \mathrm{C}$ ), diluted in $500 \mu \mathrm{L}$ of PBS, and $4 \mu \mathrm{L}$ of PI (Molecular Probes) were added before analyzing in a flow cytometer (FACSVerse, BD Biosciences) equipped with a blue laser (488 nm). The sperm population was gated using FSC and SSC, with debris exclusion performed by gating on PI-positive events collected through a 586/42 bandpass filter. Then the fluorescence from CMA3 staining, excited by the $405-\mathrm{nm}$ violet laser, was collected using a 528/45 band-pass filter and evaluated. A typical contour plot of PI fluorescence versus CMA3 fluorescence detected by flow cytometry is given in Supplemental Figure S1 (https://doi.org/10.3168/jds.2016-12484).

Free Thiols and Disulfide Concentration Assay. Free thiols and disulfide concentrations were assessed using monobromobimane ( $\mathbf{m B B r}$; Molecular Probes) as per the procedure given by Seligman et al. (1994) and Zubkova et al. (2005), with minor modifications. Spermatozoa diluted in TNE buffer were divided into 2 parts of 1 million spermatozoa. Spermatozoa in one tube were incubated $\left(37^{\circ} \mathrm{C}\right.$ for $\left.10 \mathrm{~min}\right)$ with $1 \mathrm{mmol} / \mathrm{L}$ of 1,4-dithiothreitol (DTT) to reduce disulfides to free thiols, whereas DTT was not added to the other tube. After centrifugation $(300 \times g, 10 \mathrm{~min}$ at room temperature, approximately $23^{\circ} \mathrm{C}$ ), $100 \mu \mathrm{L}$ of $\mathrm{mBBr}$ solution (final concentration $0.5 \mathrm{mmol}$ ), was added to the sperm pellet and the sample was incubated in the dark for 10 min. During this time, $\mathrm{mBBr}$ reacted and bound to free thiols. Spermatozoa were then washed in PBS by centrifugation $(300 \times g, 10 \mathrm{~min}$ at room temperature, approximately $23^{\circ} \mathrm{C}$ ) and analyzed in a flow cytometer (FACSVerse, BD Biosciences) after excitation by the 405-nm violet laser. Data were collected using a 528/45 band-pass filter, the sperm population was gated using FSC and SSC, and a minimum of 10,000 sperm events were evaluated. Histogram of $\mathrm{mBBr}$ fluorescence detected by flow cytometry is given in Supplemental Figure S2 (https://doi.org/10.3168/jds.2016-12484).

Disulfide concentrations were calculated by subtracting free thiols $(\mathrm{mBBr}$ fluorescent in the non-DTT treated sample) from total thiols $(\mathrm{mBBr}$ fluorescent in DTT treated sample) for the corresponding sample and then dividing the value by 2 .

\section{Statistical Analysis}

The mean and standard error of mean for all the 37 sperm functional attributes for below-average, average, and above-average fertility bulls were calculated using descriptive statistical analysis. The differences in the semen quality parameters among below-average, average, and above-average fertility bulls were analyzed using ANOVA. To group the parameters with similar trends, the 37 sperm functional attributes measured were subjected to principal component analysis (PCA). The correlation matrix for the analysis and rotation method used was Varimax with Kaiser normalization. The component analysis revealed possibilities of creating 8 components. The parameters were grouped in 8 components as per rotated component matrix, and parameters were placed in the group where the highest positive value was observed. After grouping into components, person product moment correlation was calculated for each parameter with adjusted NRR. The partial least squares regression was also carried out to identify the most important parameters. The parameter with the highest correlation value in each component was compared between above- and below-average fertility bulls using Student's $t$-test. In all cases, a $P$-value of 0.05 or lower was considered to be statistically significant.

The data on sperm parameters were further analyzed by receiver operating characteristic (ROC) analysis. Accuracy in ROC analysis was indicated by area under curve. The ROC analysis also produced a range of potential threshold values; the values having maximum 
combined sensitivity (Se) and specificity (Sp) were considered as optimum threshold values. The Se was defined as proportion of above-average fertility bulls that were identified by sperm parameters as being above-average bulls (true positive), and Sp was the proportion of below-average fertility bulls that were identified by sperm parameters as being below-average bulls (true negative). The likelihood ratio $(\mathrm{LR}+)$ indicated the probability that a bull with sperm parameters above or below the optimum threshold values was more likely to be identified as either below- or above-average fertility. The results of ROC analysis of sperm parameters are given in Supplemental Table S1 (https://doi. org/10.3168/jds.2016-12484).

A scatter plot was prepared for the parameters that had both the highest correlation values in a particular principal component and differed significantly between above- and below-average fertility bulls. Regression analysis was carried out to find out the relationship between these sperm functional attributes and adjusted NRR. The functional attributes that had a coefficient of determination $>0.5$ were used to develop a fertility prediction equation. Multiple linear regression analysis was performed to form a prediction equation where the adjusted NRR was considered as the dependent variable and sperm functional attributes were considered as independent variables. All the statistical analyses were performed using SPSS statistical software (V 20.0; IBM Corp., Chicago, IL).

\section{RESULTS}

The details of extender used for sperm cryopreservation, the number of inseminations, and adjusted NRR of the bulls used in the study are given in Table 1 . The adjusted NRR of the bulls ranged from 87 to 106; the bulls having an adjusted NRR $\leq 94$ were classified as below-average bulls $(\mathrm{n}=5)$ and the bulls having an adjusted NRR $\geq 103$ were classified as above-average bulls $(\mathrm{n}=6)$, whereas the remainder were classified into the average category. A total of 37 parameters associated with different sperm functions were evaluated for each bull; the results are detailed below.

\section{Sperm Functional Attributes Among Bulls Under Different Fertility Classifications}

The differences in sperm functional attributes evaluated among the 3 fertility categories of the bulls are given in Table 2. The adjusted NRR differed significantly $(P<0.01)$ among the 3 fertility categories of the bulls. Of the different sperm functional attributes, significant differences were observed in sperm viability, acrosomal integrity, ROS, and \%DFI among below-average, average, and above-average fertility bulls. No significant difference was observed in any of the kinematic parameters studied. The proportion of live spermatozoa was significantly $(P<0.001)$ lower in below-average compared with average and above-average fertility bulls, whereas the proportion of dead spermatozoa was significantly $(P<0.001)$ higher in below-average compared with average and above-average fertility bulls. Semen samples from above-average fertility bulls had significantly $(P<0.05)$ higher LAI spermatozoa and significantly $(P<0.05)$ lower DAR spermatozoa compared with below-average and average fertility bulls. The proportion of $\mathrm{SO}+$ and $\mathrm{SO}-$ spermatozoa did not differ among the 3 categories of the bulls. Similarly, the MMP status of spermatozoa also did not differ with the fertility status of the bulls. However, the proportion of live and $\mathrm{H}_{2} \mathrm{O}_{2}$ - spermatozoa was significantly $(P<0.05)$ lower in below-average bulls compared with average and above-average bulls. Above-average fertility bulls had significantly $(P<0.05)$ higher MitoSOX+ and $\mathrm{JC}-$ sperm population compared with average and below-average bulls. The population of MitoSOX + and $\mathrm{JC}+$ spermatozoa was also significantly $(P<0.05)$ higher in above-average fertility bulls, but the difference between average and below-average bulls was not significant. We found no significant differences in disulfide, free thiols, and protamine deficiency in the spermatozoa from the 3 categories of the bulls, although the \%DFI was significantly $(P<0.05)$ lower in above-average bulls compared with average and belowaverage fertility bulls.

\section{Principal Component Analysis of Sperm Functional Attributes}

The parameters measured were subjected to PCA to group the parameters with similar trends. The component analysis revealed possibilities of creating 8 components. The parameters were grouped in 8 components as per rotated component matrix, and parameters were placed in the group where the highest positive value was observed. The extracted 8 components accounted for $91 \%$ of the total variance (Table 3 ). The first principal component was related to sperm viability, acrosomal integrity, ROS, and DNA integrity, which accounted for $30.34 \%$ of variance. The second and third components were related to sperm kinematics and accounted for 21.30 and $11.68 \%$ of variance, respectively. The component 4 was related to sperm motility and component 5 was associated with ROS, MMP, and DNA integrity. Components 6,7 , and 8 were related to MMP, viability, and DNA integrity, respectively. Partial least squares 
Table 2. Sperm functional attributes among above average, average, and below average adjusted nonreturn rate (NRR) bulls ${ }^{1}$

\begin{tabular}{|c|c|c|c|}
\hline Sperm functional attribute ${ }^{2}$ & $\begin{array}{l}\text { Below-average } \\
\text { bulls }(\mathrm{n}=5)\end{array}$ & $\begin{array}{c}\text { Average } \\
\text { bulls }(\mathrm{n}=9)\end{array}$ & $\begin{array}{l}\text { Above-average } \\
\text { bulls }(\mathrm{n}=6)\end{array}$ \\
\hline $\begin{array}{l}\text { NRR** } \\
\text { Live }(\%)^{* *} \\
\text { Dead }(\%)^{* *} \\
\text { LAI }(\%)^{*} \\
\text { LAR }(\%)^{*} \\
\text { DAR }(\%)^{*} \\
\text { Live } \mathrm{H}_{2} \mathrm{O}_{2}-\text { population }(\%)^{*} \\
\text { MitoSOX+JC- population }(\%)^{* *} \\
\text { MitoSOX+JC+ population }(\%)^{* *} \\
\text { MitoSOX-JC+ population }(\%)^{*} \\
\text { DFI }(\%)^{*}\end{array}$ & $\begin{aligned} 91.8^{\mathrm{a}} & \pm 1.28 \\
49.65^{\mathrm{a}} & \pm 1.61 \\
47.06^{\mathrm{a}} & \pm 0.79 \\
45.43^{\mathrm{a}} & \pm 1.98 \\
0.34^{\mathrm{a}} & \pm 0.15 \\
24.03^{\mathrm{a}} & \pm 1.92 \\
54.00^{\mathrm{a}} & \pm 2.05 \\
6.22^{\mathrm{a}} & \pm 4.16 \\
2.42^{\mathrm{ab}} & \pm 1.26 \\
25.84^{\mathrm{ab}} & \pm 9.01 \\
6.23^{\mathrm{a}} & \pm 1.43\end{aligned}$ & $\begin{aligned} 98.0^{\mathrm{b}} & \pm 0.76 \\
63.22^{\mathrm{b}} & \pm 2.07 \\
33.98^{\mathrm{b}} & \pm 2.07 \\
57.31^{\mathrm{b}} & \pm 2.43 \\
0.46^{\mathrm{ab}} & \pm 0.12 \\
19.82^{\mathrm{ab}} & \pm 1.37 \\
59.75^{\mathrm{ab}} & \pm 3.66 \\
2.20^{\mathrm{a}} & \pm 0.97 \\
0.84^{\mathrm{a}} & \pm 0.25 \\
49.80^{\mathrm{a}} & \pm 5.91 \\
4.65^{\mathrm{a}} & \pm 0.43\end{aligned}$ & $\begin{aligned} 104.0^{\mathrm{c}} & \pm 0.45 \\
64.24^{\mathrm{b}} & \pm 1.24 \\
31.84^{\mathrm{b}} & \pm 1.97 \\
57.74^{\mathrm{b}} & \pm 2.80 \\
2.61^{\mathrm{bc}} & \pm 1.05 \\
17.41^{\mathrm{bc}} & \pm 1.18 \\
63.29^{\mathrm{bc}} & \pm 1.71 \\
23.97^{\mathrm{b}} & \pm 2.40 \\
7.02^{\mathrm{b}} & \pm 2.28 \\
28.89^{\mathrm{b}} & \pm 6.27 \\
2.88^{\mathrm{b}} & \pm 0.28\end{aligned}$ \\
\hline
\end{tabular}

${ }^{\mathrm{a}-\mathrm{c}}$ Means with different superscripts in a given row differ significantly.

${ }^{1}$ Data are expressed as mean \pm SEM. Only the parameters showing significant differences among the groups are listed in the table; ${ }^{*} P<0.05 ;$ ** $P<0.01$.

${ }^{2} \mathrm{LAI}=$ live acrosome intact; LAR = live acrosome reacted; DAR = dead acrosome reacted; MitoSOX = mitochondria-specific superoxide; JC $=\mathrm{JC}-1$ mitochondrial membrane potential; DFI $=$ DNA fragment index.

regression analysis also revealed that sperm viability, acrosome status, ROS, and \%DFI were the very important variables, having highest correlation with adjusted NRR.
The ROC analysis also indicated the accuracy of live, dead, live $\mathrm{SO}$ negative, live $\mathrm{H}_{2} \mathrm{O}_{2}$ negative, DAI, DAR spermatozoa, and \%DFI in differentiating aboveaverage from below-average fertility bulls. The area

Table 3. Results of principal component analysis based on different sperm functional attributes in bulls with different fertility ratings

\begin{tabular}{|c|c|c|c|}
\hline $\begin{array}{l}\text { Principal } \\
\text { component }\end{array}$ & $\begin{array}{l}\text { Variance } \\
(\%)\end{array}$ & Parameter $^{1}$ & $\begin{array}{l}\text { Loading } \\
\text { factor }^{2}\end{array}$ \\
\hline \multirow[t]{6}{*}{ Component 1} & 30.34 & Dead & 0.93 \\
\hline & & Dead SO+ & 0.91 \\
\hline & & Dead $\mathrm{H}_{2} \mathrm{O}_{2}-$ & 0.91 \\
\hline & & DAI & 0.88 \\
\hline & & DAR & 0.75 \\
\hline & & Protamine deficiency & 0.53 \\
\hline \multirow[t]{7}{*}{ Component 2} & 21.30 & VCL & 0.95 \\
\hline & & DAP & 0.93 \\
\hline & & DCL & 0.93 \\
\hline & & VAP & 0.93 \\
\hline & & ALH & 0.81 \\
\hline & & VSL & 0.76 \\
\hline & & LAR & 0.53 \\
\hline \multirow[t]{4}{*}{ Component 3} & 11.68 & STR & 0.97 \\
\hline & & LIN & 0.93 \\
\hline & & $\mathrm{BCF}$ & 0.83 \\
\hline & & WOB & 0.75 \\
\hline \multirow[t]{2}{*}{ Component 4} & 9.5 & Total motility & 0.95 \\
\hline & & Progressive motility & 0.95 \\
\hline \multirow{3}{*}{ Component 5} & 7.0 & Free thiols & 0.85 \\
\hline & & MSOX + JC- & 0.66 \\
\hline & & MSOX + JC+ & 0.62 \\
\hline Component 6 & 4.5 & Low MMP & 0.72 \\
\hline Component 7 & 3.8 & Moribund & 0.57 \\
\hline Component 8 & 2.8 & $\%$ DFI & 0.88 \\
\hline Total & 91 & & \\
\hline
\end{tabular}

${ }^{1} \mathrm{SO}=$ superoxide; DAI $=$ dead acrosome intact; DAR $=$ dead acrosome reacted; $\mathrm{VCL}=$ curvilinear velocity; $\mathrm{DAP}=$ average path distance DCL $=$ curvilinear distance; VAP $=$ average path velocity; ALH $=$ amplitude of lateral head deviation; VSL = straight line velocity; LAR = live acrosome reacted; STR = straightness; LIN $=$ linearity $; \mathrm{BCF}=$ beat cross frequency; $\mathrm{WOB}=$ wobble; $\mathrm{MMP}=$ microbial membrane potential; $\% \mathrm{DFI}=$ DNA fragmentation index. MSOX $=$ mitochondria-specific superoxide; JC = JC-1 mitochondrial membrane potential.

${ }^{2}$ The loading factor represents the highest association between a given sperm functional attribute and the corresponding principal component (attributes having a high loading factor within a component are included in the table). 
under ROC curve was more than $80 \%$, and the Se and Sp were also high for these parameters (Supplemental Table S1; https://doi.org/10.3168/jds.2016-12484).

\section{Relationship of Sperm Functional Attributes with Bull Fertility}

Person product-moment correlation was calculated for each parameter with NRR to identify the parameter with highest correlation value. The results indicated that, out of the 37 parameters, the proportion of live $(\mathrm{r}=0.53 ; P=0.02)$ and LAR $(\mathrm{r}=0.50 ; P=0.02)$ spermatozoa were significantly positively related to adjusted NRR, whereas the proportion of dead $(\mathrm{r}=$ $-0.53 ; P=0.02)$ spermatozoa and \%DFI $(\mathrm{r}=0.61 ; P$ $=0.01$ ) were significantly negatively related to adjusted NRR in bulls.

\section{Identification of the Most Important Sperm Functional Attributes for Fertility Estimation}

Having studied the relationship of different sperm functional attributes with bull fertility, we identified the sperm functional attributes that differed significantly between below- and above-average bulls. The proportion of live spermatozoa was significantly $(P$ $<0.01)$ higher, and of dead spermatozoa was significantly $(P<0.01)$ lower in above-average fertility bulls compared with below-average fertility bulls (Figure
1). Similarly, the proportions of LAI, LAR, live and $\mathrm{H}_{2} \mathrm{O}_{2}-$, MitoSOX + and JC-, and MitoSOX + and $\mathrm{JC}+$ spermatozoa were also significantly $(P<0.05)$ higher in above-average fertility bulls compared with below-average fertility bulls. The proportion of DAR spermatozoa and \%DFI were significantly $(P<0.05)$ lower in above-average fertility bulls compared with below-average fertility bulls.

To understand the sperm functional attributes associated with below- and above-average fertility, PCA with groups was used. The distribution of bulls in relation to identified important sperm functional attributes and the fertility status is shown in Figure 2 ; below-average fertility bulls are indicated as red whereas above-average fertility bulls are indicated as blue ellipses. This schematic representation shows the distribution of the individual bulls and the predominant sperm function(s) influencing the samples. It may be observed that samples from below-average bulls (red dots) were more influenced by dead spermatozoa and \%DFI, whereas the samples from above-average bulls (blue dots) were more influenced by live spermatozoa, ROS status and acrosome integrity.

\section{Development of a Fertility Prediction Equation}

Regression equations were prepared for the parameters that differed significantly between above-average fertility bulls compared with below-average fertility

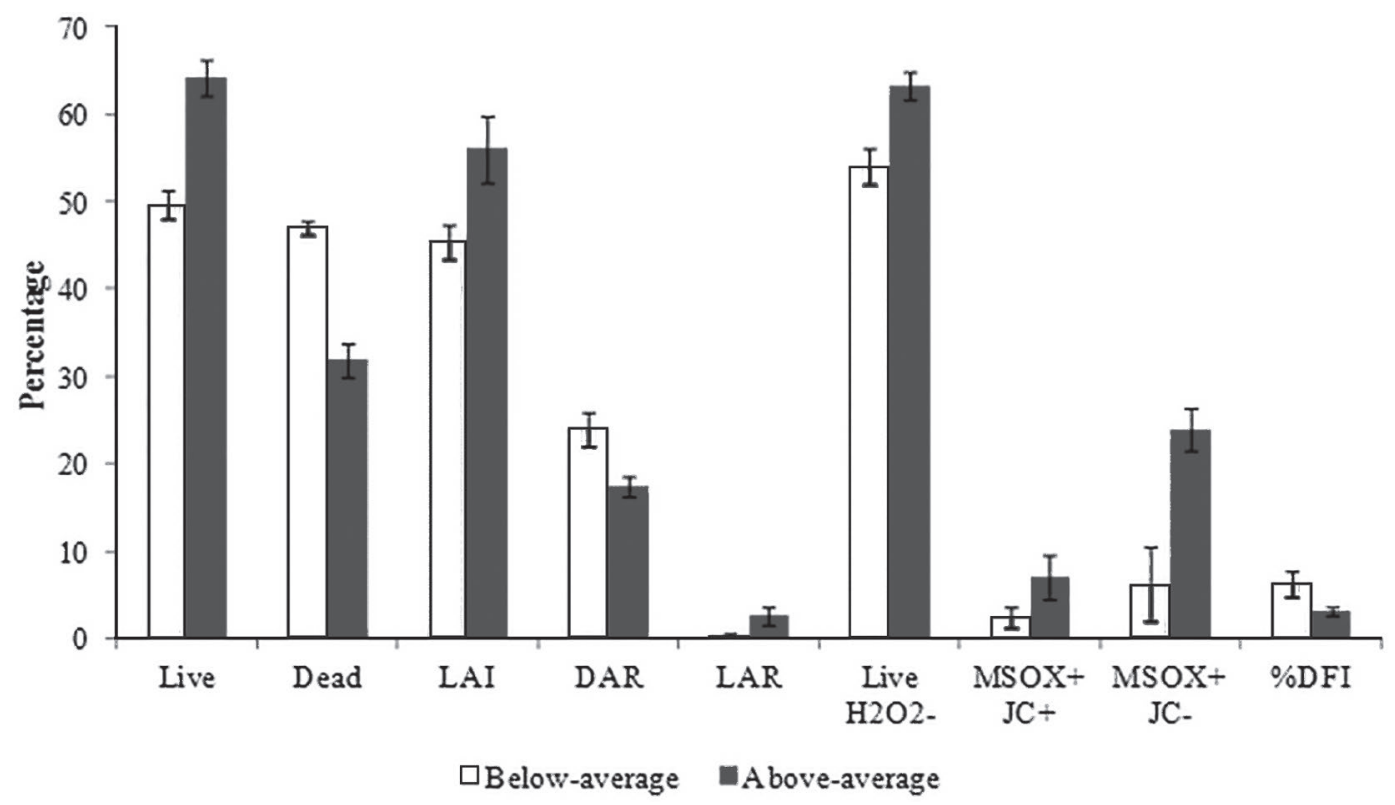

Figure 1. Differences in the sperm functional attributes between below-average $(\mathrm{n}=5)$ and above-average $(\mathrm{n}=6)$ fertile bulls. All of the parameters indicated in the graph differed significantly between the 2 groups of bulls. LAI = live acrosome intact; DAR $=$ dead acrosome reacted; LAR = live acrosome reacted; $\mathrm{MSOX}=$ mitochondria-specific superoxide; JC = JC-1 mitochondrial membrane potential; DFI $=$ DNA fragmentation index. 


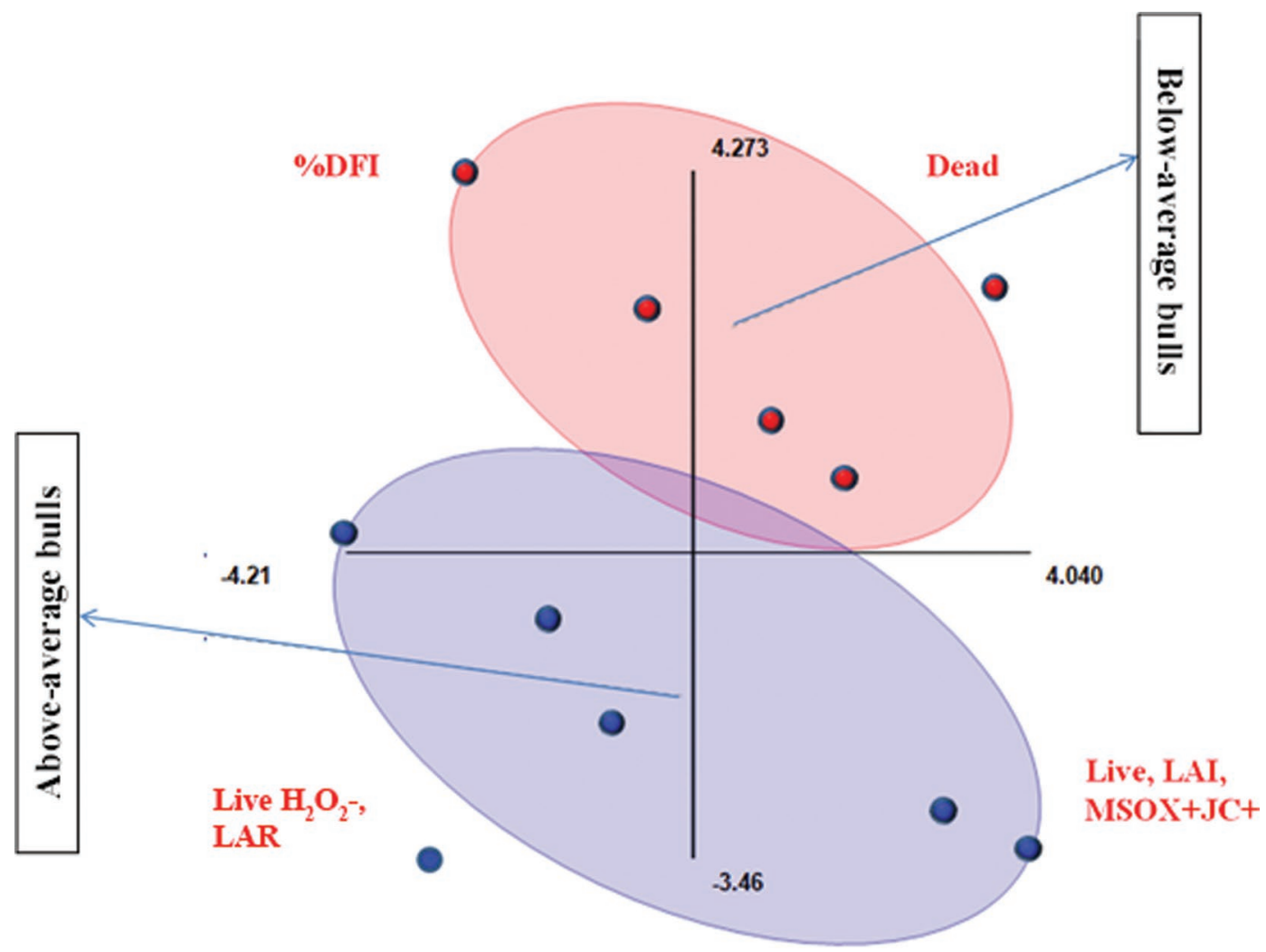

Figure 2. The distribution of bulls in relation to identified important sperm functional attributes and fertility status. The bottom (blue) ellipse and dots indicate above-average-fertility bulls; the top (red) ellipse and dots indicate below-average-fertility bulls. DFI = DNA fragmentation index; LAR = live acrosome reacted; LAI = live acrosome intact; MSOX = mitochondria-specific superoxide; JC = JC-1 mitochondrial membrane potential. Color version available online.

bulls. The scatter plots indicating the distribution of bulls for respective sperm function attribute in relation to adjusted NRR are shown in Figure 3. We observed that live $\left(\mathrm{R}^{2}=0.72 ; P=0.0009\right)$, dead $\left(\mathrm{R}^{2}=0.72\right.$; $P=0.0009)$, live and $\mathrm{H}_{2} \mathrm{O}_{2}-\left(\mathrm{R}^{2}=0.64 ; P=0.002\right)$ spermatozoa, and \%DFI $\left(\mathrm{R}^{2}=0.56 ; P=0.02\right)$ could differentiate below-average and above-average fertility bulls; thus, they were considered for development of a fertility prediction model. Multiple linear regression analysis was performed to form a prediction equation where adjusted NRR was considered as dependent variable and live, dead, live and $\mathrm{H}_{2} \mathrm{O}_{2}-$ spermatozoa, and $\%$ DFI were considered as independent variables. The following regression model was developed through the analysis:

$$
\begin{aligned}
\mathrm{NRR}=55.71+ & (0.39 \times \text { live })+\left(0.37 \times \text { live } \mathrm{H}_{2} \mathrm{O}_{2}-\right) \\
& -(0.39 \times \% \text { DFI }) .
\end{aligned}
$$

The accuracy of the identified combination of sperm functional attributes for fertility prediction in bulls was reasonably high. The coefficient of determination value of the model was 0.83 and the adjusted coefficient of determination value was $0.76(P=0.004)$.

\section{DISCUSSION}

Accurate prediction of bull field fertility is of major economic importance because inseminating semen of low fertilizing capacity represents a significant loss to the breeding industry. Despite several attempts to identify markers, methods, or tests that could aid in predicting bull fertility, results are inconsistent and further research is needed (Rodríguez-Martinez, 2013). As the fertility of the bull depends on the ability of the spermatozoon to communicate information to the developing embryo to sustain its development and growth, we analyzed several variables related to sperm functions, including DNA integrity, and report here that sperm viability, ROS status, and \%DFI could help in differentiating below- and above-average fertility bulls. Among the attributes studied, sperm viability, acrosomal integrity, ROS status, and \%DFI differed among the bulls with different fertility status, had a signifi- 
NRR vs. Live $y=0.6461 x+61.235$

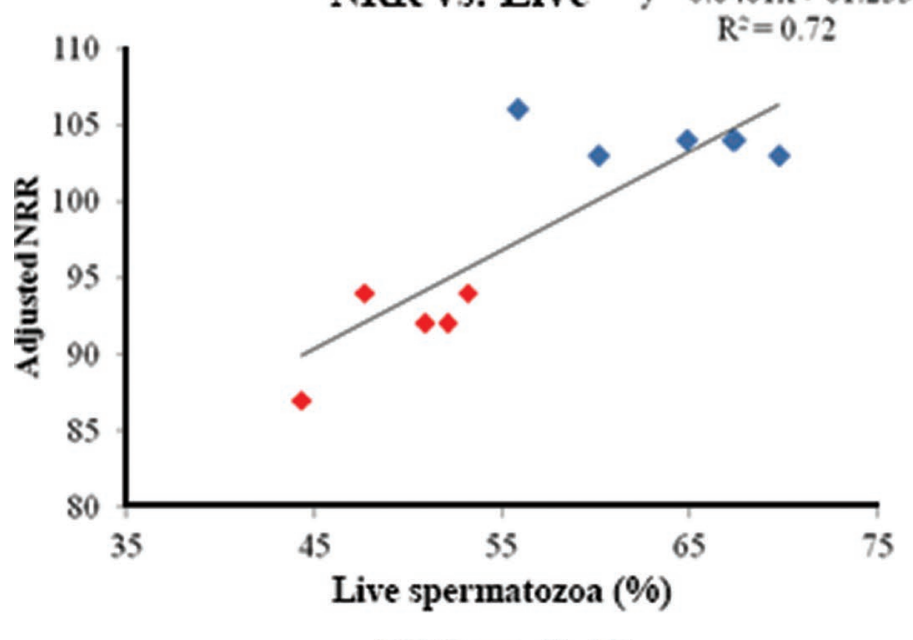

NRR vs. LAI

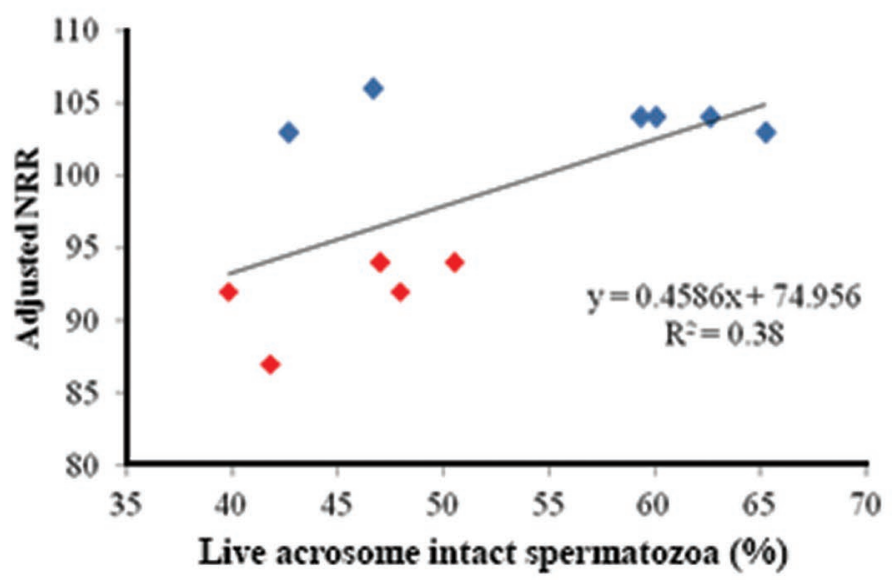

NRR vs. MSOX $+\mathrm{JC}+$

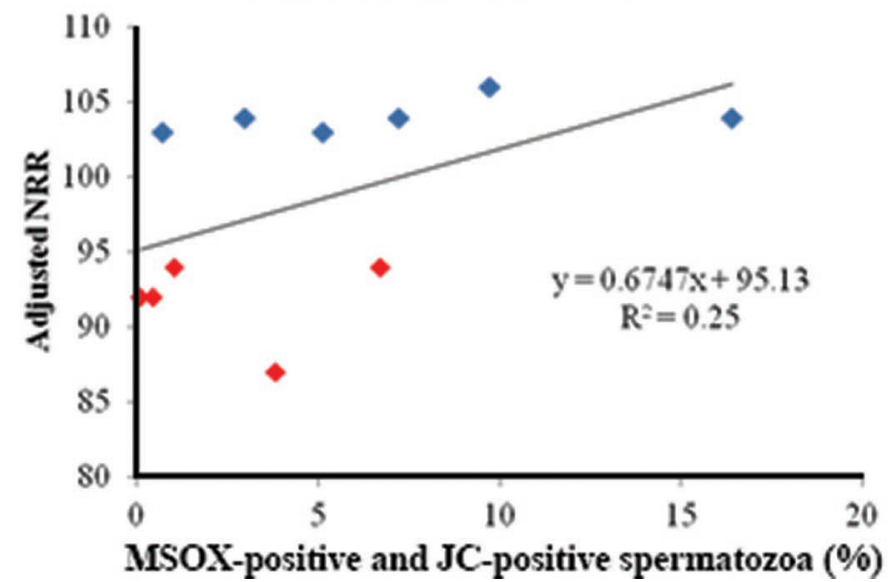

NRR vs. Dead

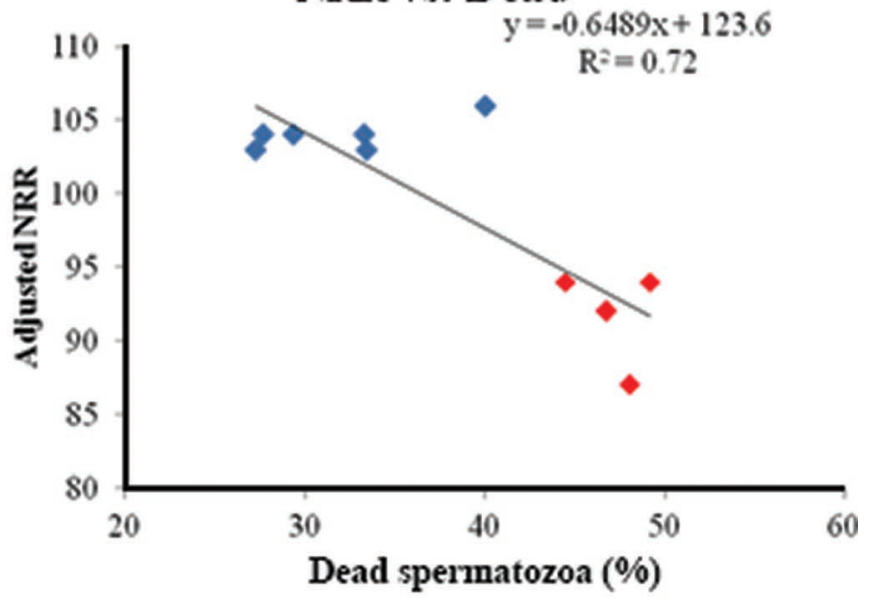

NRR vs. Live $\mathrm{H}_{2} \mathrm{O}_{2}$

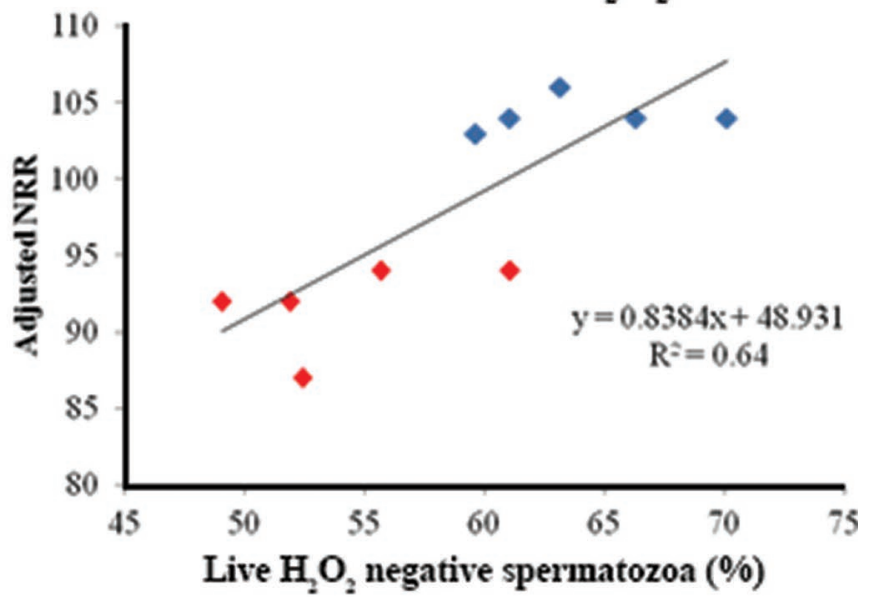

NRR vs. \%DFI

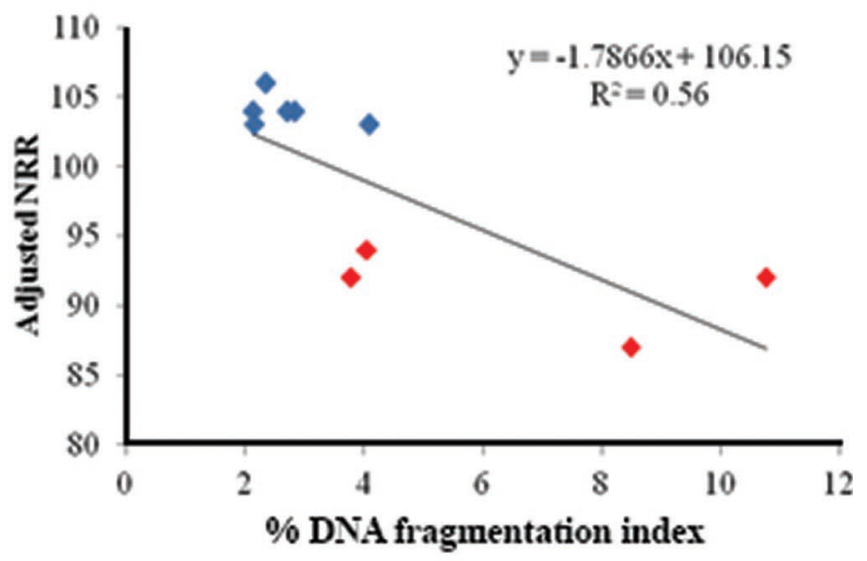

Figure 3. Scatter plot distribution of individual observations for different sperm functional attributes in below-average $(\mathrm{n}=5)$ and aboveaverage $(\mathrm{n}=6)$ fertile bulls. Lower (red) diamond shapes indicate below-average bulls, whereas upper (blue) diamond shapes indicate aboveaverage bulls. Linear regression equation and $\mathrm{R}^{2}$ values are also shown. NRR = nonreturn rate; LAI = live acrosome intact; MSOX $=$ mitochondria-specific superoxide; JC = JC-1 mitochondrial membrane potential; DFI = DNA fragmentation index. Color version available online. 
cant relationship with bull fertility, and accounted for $30.34 \%$ of variance. As the NRR had been adjusted for the influence of herd, year, season of insemination, breed of the dam, lactation number, inseminator, and insemination number, it can be assumed that the variations in the sperm functional attributes were due to a bull effect.

Post-thaw sperm motility and kinematic parameters did not differ significantly among the groups of bulls, indicating that factors other than motility account for the differences in fertility. The relationship of postthaw sperm kinematics with bull fertility is highly variable (Bailey et al., 1994; Stålhammar et al., 1994; Karunakaran and Devanathan, 2017), partly due to differences in estimation methods, computer-assisted sperm analysis settings, sample preparations including thawing temperature, sperm sample concentration, and media used for dilution (Contri et al., 2010).

In our study, sperm viability was significantly lower in below-average bulls compared with average and above-average bulls, indicating that a considerable proportion of motile spermatozoa in below-average bulls had damaged membranes that allowed PI labeling. Several previous studies indicated that sperm viability is related to bull fertility (Christensen et al., 1999, 2005; Januskauskas et al., 2003; Tartaglione and Ritta, 2004; Rodríguez-Martinez, 2007). Christensen et al. (2011) reported that the most precise estimation of a bull's NRR at $56 \mathrm{~d}$ was achieved through assessment of sperm concentration and viability in neat semen as well as post-thaw sperm viability. However, as these are not the only parameters of importance in determining fertility, reliance on only these parameters will, intuitively, not provide enough information about potential fertility to be a useful predictor.

Spermatozoa must be able to acrosome react, at the right time, to fertilize an oocyte (Esteves and Verza, 2011). Our observation that the proportion of LAI spermatozoa was significantly lower in below-average fertility bulls compared with average and above-average fertility bulls, is similar to earlier reports (Birck et al., 2010; Haryama et al., 2010; Singh et al., 2016).

Oxidative stress is known to be a major factor regulating the vitality and functionality of mammalian spermatozoa (Aitken and Curry, 2011). The precise roles of $\mathrm{SO}$ and $\mathrm{H}_{2} \mathrm{O}_{2}$ in relation to male fertility, although studied extensively, are not properly understood (Guthrie and Welch, 2012). We observed that the proportion of live, $\mathrm{H}_{2} \mathrm{O}_{2}-$ spermatozoa were significantly higher in above-average fertility bulls compared with belowaverage fertility bulls. Seminal plasma contains several antioxidant enzymes that regulate ROS levels; however, extending semen may allow oxidative attack to occur (Sawyer et al., 2003). We observed that the mROS- positive spermatozoa (MitoSOX+) were significantly higher in above-average fertility bulls compared with below-average fertility bulls, indicating that the spermatozoa were more metabolically active than spermatozoa from below-average fertility bulls. Our results are in contrast to those of Marques et al. (2104) in human ejaculates; however, we used unselected frozen-thawed spermatozoa for estimation of mROS, whereas Marques et al. (2014) used density gradient-selected spermatozoa, which might be the reason for the contrasting results. Sperm mROS has not been studied in detail in bulls, especially in relation with fertility, and the preliminary findings of the present study that mROS may be related to bull fertility requires further confirmation. A tentative link between SO positivity, fertility, and selection by colloid centrifugation has, however, been observed for stallion spermatozoa (Morrell et al., 2016)

In the last few decades, the role of sperm DNA integrity in male factor infertility in human patients has been shown (Schulte et al., 2010). In the case of bulls, sperm DNA fragmentation values of 7 to $10 \%$ were indicative of low AI success (Karoui et al., 2012). Embryos produced by high-fertility bulls enter the first S-phase of the cell cycle faster and are greater in length than embryos produced by low-fertility bulls (Eid et al., 1994). Genetic and epigenetic alterations of sperm may therefore have dire consequences in early loss of pregnancy (Khadem et al., 2014). As the \%DFI was significantly higher in below-average bulls in our study, we suggest that assessment of sperm DNA damage in addition to conventional semen analysis may provide additional useful information in identifying belowaverage fertility bulls.

Ultimately, we identified 4 sperm functional variables including live, dead, live $\mathrm{H}_{2} \mathrm{O}_{2}-$ spermatozoa, and \%DFI that could help differentiate below-average fertility bulls from above-average fertility bulls. Furthermore, PCA group analysis clearly indicated that samples from below-average bulls were more influenced by dead spermatozoa and \%DFI, whereas the samples from above-average bulls were more influenced by live spermatozoa, ROS status, and acrosome integrity. Thus, we developed a prediction model with a high regression coefficient using these variables. In the current study, we used one ejaculate from each bull; it would be interesting to study the intrabull variations for these parameters over a period of time. Furthermore, the developed model needs to be validated using a large number of bulls with known fertility based on large numbers of inseminations before recommendation for clinical use.

In conclusion, comprehensive assessment of different aspects of sperm functions and subsequent statistical analysis indicated that semen from below-average 
fertility bulls differed in sperm viability, acrosomal integrity, ROS status, and DNA integrity. The PCA also indicated that sperm viability, acrosomal integrity, ROS, and DNA integrity accounted for $30.34 \%$ of the variance among bulls and related to bull fertility more than other sperm functional parameters. We developed a model to differentiate below-average fertility bulls from above-average fertility bulls using these parameters, with reasonable predictive value: the developed model showed $100 \%$ efficiency in identifying belowaverage fertility bulls.

\section{ACKNOWLEDGMENTS}

A. Kumaresan acknowledges the Indian Council of Agricultural Research (ICAR) and National Dairy Research Institute, New Delhi, India, for permitting him to undergo research cum training program at the Department of Clinical Sciences/Division of Reproduction, Swedish University of Agricultural Sciences, Uppsala, Sweden. The training was a part of "Lal Bahadur Shastri Young Scientist Award" awarded by the ICAR to A. Kumaresan. The study was financed by a grant from The Swedish Farmers' Foundation (Stockholm) to Jane M. Morrell and Anders Johannisson (H1330039). We thank Viking Genetics (Skara, Sweden) for kindly providing the bull semen.

\section{REFERENCES}

Aitken, R. J., and B. J. Curry. 2011. Redox regulation of human sperm function: From the physiological control of sperm capacitation to the etiology of infertility and DNA damage in the germ line. Antioxid. Redox Signal. 14:367-381.

Amann, R. P. 2005. Weaknesses in reports of "fertility" for horses and other species. Theriogenology 63:698-715.

Aslam, M. K., A. Kumaresan, V. K. Sharma, M. Tajmul, S. Chhillar, A. K. Chakravarty, A. Manimaran, T. K. Mohanty, A. Srinivasan, and S. Yadav. 2014. Identification of putative fertility markers in seminal plasma of crossbred bulls through differential proteomics. Theriogenology 82:1254-1262.e1.

Bailey, J. L., L. Robertson, and M. M. Buhr. 1994. Relations among in vivo fertility, computer-analysed motility and $\mathrm{Ca}++$ influx in bovine spermatozoa. Can. J. Anim. Sci. 74:53-58.

Birck, A., P. Christensen, R. Labouriau, J. Pedersen, and S. Borchersen. 2010. In vitro induction of the acrosome reaction in bull sperm and the relationship to field fertility using low-dose inseminations. Theriogenology 73:1180-1191.

Christensen, P., D. Boelling, K. M. Pedersen, I. R. Korsgaard, and J. Jensen. 2005. Relationship between sperm viability as determined by flow cytometry and nonreturn rate of dairy bulls. J. Androl. 26:98-106.

Christensen, P., P. B. Brockhoff, and H. Lehn-Jensen. 1999. The relationship between semen quality and the non-return rate of bulls. Reprod. Domest. Anim. 34:503-507.

Christensen, P., R. Labouriau, A. Birck, G. B. Boe-Hansen, J. Pedersen, and S. Borchersen. 2011. Relationship among seminal quality measures and field fertility of young dairy bulls using low-dose inseminations. J. Dairy Sci. 94:1744-1754.

Contri, A., C. Valorz, M. Faustini, L. Wegher, and A. Carluccio. 2010. Effect of semen preparation on casa motility results in cryopreserved bull spermatozoa. Theriogenology 74:424-435.
Correa, J. R., M. M. Pace, and P. M. Zavos. 1997. Relationship among frozen-thawed sperm characteristics assessed via the routine semen analysis, sperm functional tests and fertility of bulls in an artificial insemination program. Theriogenology 48:721-731.

Cossarizza, A., M. Baccarani-Contri, G. Kalashnikova, and C. Franceschi. 1993. A new method for the cytofluorimetric analysis of mitochondrial membrane potential using the J-aggregate forming lipophilic cation $5,5^{\prime}, 6,6^{\prime}$-tetrachloro-1, $1^{\prime}, 3,3^{\prime}$-tetraethylbenzimida zolcarbocyanine iodide (JC-1). Biochem. Biophys. Res. Commun. 197:40-45.

Eid, L. N., S. P. Lorton, and J. J. Parrish. 1994. Paternal influence on S-phase in the first cell cycle of the bovine embryo. Biol. Reprod. 51:1232-1237.

Erenpreiss, J., S. Elzanaty, and A. Giwercman. 2008. Sperm DNA damage in men from infertile couples. Asian J. Androl. 10:786-790.

Esteves, S. C., and S. Verza Jr. 2011. Relationship of in vitro acrosome reaction to sperm function: An update. Open Reprod. Sci. J. 3:72-84.

Evenson, D., and L. Jost. 2000. Sperm chromatin structure assay is useful for fertility assessment. Methods Cell Sci. 22:169-189.

Evenson, D. P., L. K. Jost, D. Marshall, M. J. Zinaman, E. Clegg, K. Purvis, P. de Angelis, and O. P. Claussen. 1999. Utility of the sperm chromatin structure assay as a diagnostic and prognostic tool in the human fertility clinic. Hum. Reprod. 14:1039-1049.

Goodla, L., J. M. Morrell, Y. Yusnizar, H. Stålhammar, and A. Johannisson. 2014. Quality of bull spermatozoa after preparation by single-layer centrifugation. J. Dairy Sci. 97:2204-2212.

Grippo, A. A., A. L. Way, and G. J. Killian. 1995. Effect of bovine ampullary and isthmic oviductal fluid on motility, acrosome reaction and fertility of bull spermatozoa. J. Reprod. Fertil. 105:57-64.

Guthrie, H. D., and G. R. Welch. 2012. Effects of reactive oxygen species on sperm function. Theriogenology 78:1700-1708.

Evenson, D., and L. Jost. 2000. Sperm chromatin structure assay is useful for fertility assessment. Methods Cell Sci. 22:169-189.

Januskauskas, A., A. Johannisson, and H. Rodriguez-Martinez. 2003. Subtle membrane changes in cryopreserved bull semen in relation with sperm viability, chromatin structure and field fertility. Theriogenology 60:743-758.

Johnson, G. D., C. Lalancette, A. K. Linnemann, F. Leduc, G. Boissoneault, and S. A. Krawetz. 2011. The sperm nucleus: Chromatin, RNA, and the nuclear matrix. Reproduction 141:21-36.

Karoui, S., C. Díaz, C. González-Marín, M. E. Amenabar, M. Serrano, E. Ugarte, J. Gosálvez, R. Roy, C. López-Fernández, and M. J. Carabaño. 2012. Is sperm DNA fragmentation a good marker for field AI bull fertility? J. Anim. Sci. 90:2437-2449.

Karunakaran, M., and T. G. Devanathan. 2017. Evaluation of bull semen for fertility-associated protein, in vitro characters and fertility. J. Appl. Anim. Res. 45:136-144.

Katari, S., N. Turan, M. Bibikova, O. Erinle, R. Chalian, M. Foster, J. P. Gaughan, C. Coutifaris, and C. Sapienza. 2009. DNA methylation and gene expression differences in children conceived in vitro or in vivo. Hum. Mol. Genet. 18:3769-3778.

Khadem, N., A. Poorhoseyni, M. Jalali, A. Akbary, and S. T. Heydari. 2014. Sperm DNA fragmentation in couples with unexplained recurrent spontaneous abortions. Andrologia 46:126-130.

Kumaresan, A., A. Johannisson, and A. S. Bergqvist. 2016. Sperm function during incubation with oestrus oviductal fluid differs in bulls with different fertility. Reprod. Fertil. Dev. https://doi. org/10.1071/RD15474.

Larson, J. L., and D. J. Miller. 2000. Can relative spermatozoal galactosyl transferase activity be predictive of dairy bull fertility? J. Dairy Sci. 83:2473-2479.

Lewis, S. E. M. 2013. The place of sperm DNA fragmentation testing in current day fertility management. Middle East Fertil. Soc. J. 18:78-82.

Marques, M., A. P. Sousa, A. Paiva, T. Almeida-Santos, and J. Ramalho-Santos. 2014. Low amounts of mitochondrial reactive oxygen species define human sperm quality. Reproduction 147:817-824.

Morrell, J. M., A. Lagerquist, P. Humblot, and A. Johannisson. 2016. Effect of single layer centrifugation on reactive oxygen species and sperm mitochondrial membrane potential in cooled stallion se- 
men. Reprod. Fertil. Dev. 29:1039-1045. https://doi.org/10.1071/ RD15440.

Nagy, Á., T. Polichronopoulos, A. Gáspárdy, L. Solti, and S. Cseh. 2015. Correlation between bull fertility and sperm cell velocity parameters generated by computer-assisted semen analysis. Acta Vet. Hung. 63:370-381.

Nagy, S., A. Johannisson, T. Wahlsten, R. Ijäs, M. Andersson, and H. Rodriguez-Martinez. 2013. Sperm chromatin structure and sperm morphology: their association with fertility in AI-dairy Ayrshire sires. Theriogenology 79:1153-1161.

Oleszczuk, K., A. Giwercman, and M. Bungum. 2011. Intra-individual variation of the sperm chromatin structure assay DNA fragmentation index in men from infertile couples. Hum. Reprod. 26:32443248 .

Oliveira, L. Z., R. P. de Arrudab, A. F. C. de Andrade, E. C. C. Celeghini, R. M. dos Santos, M. E. Beletti, R. F. G. Peresd, C. S. Oliveira, and V. F. M. H. de Lima. 2012. Assessment of field fertility and several in vitro sperm characteristics following the use of different Angus sires in a timed-AI program with suckled Nelore cows. Livest. Sci. 146:38-46.

Parisi, A. M., S. K. Thompson, A. Kaya, and E. Memili. 2014. Molecular, cellular, and physiological determinants of bull fertility. Turk. J. Vet. Anim. Sci. 38:637-642.

Rodríguez-Martinez, H. 2007. State of art in farm animal sperm evaluation. Reprod. Fertil. Dev. 19:91-101.

Rodríguez-Martínez, H. 2013. Semen evaluation techniques and their relationship with fertility. Anim. Reprod. 10:148-159.

Sawyer, D. E., B. G. Mercer, A. M. Wiklendt, and R. J. Aitken. 2003. Analysis of gene-specific DNA damage and single-strand DNA breaks induced by pro-oxidant treatment of human spermatozoa in vitro. Mutat. Res. 529:21-34.

Schulte, R. T., D. A. Ohl, M. Sigman, and G. D. Smith. 2010. Sperm DNA damage in male infertility: Etiologies, assays, and outcomes. J. Assist. Reprod. Genet. 27:3-12.

Seligman, J., N. S. Kosower, R. Weissenberg, and R. Shalgi. 1994. Thiol-disulfide status of human sperm proteins. J. Reprod. Fertil. 101:435-443.
Silva, P. F. N., and B. M. Gadella. 2006. Detection of damage in mammalian sperm cells. Theriogenology 65:958-978.

Singh, R. K., A. Kumaresan, S. Chhillar, S. K. Rajak, U. K. Tripathi, S. Nayak, T. K. Datta, T. K. Mohanty, and R. Malhotra. 2016 Identification of suitable combinations of in vitro sperm function test for the prediction of fertility in buffalo bull. Theriogenology 86:2263-2271.e1.

Söderquist, L., L. Janson, K. Larsson, and S. Einarsson. 1991. Sperm morphology and fertility in A.I. Zentralbl. Veterinarmed. A 38:534-543.

Stålhammar, E. M., L. Janson, and J. Philipsson. 1994. The impact of sperm motility on non-return rate in preselected dairy bulls. Reprod. Nutr. Dev. 34:37-45.

Sudano, M. J., A. M. Crespilho, C. B. Fernandes, A. Martins Junior., F. O. Papa, J. Rodrigues, R. Machado, and F. C. LandimAlvarenga. 2011. Use of Bayesian inference to correlate in vitro embryo production and in vivo fertility in Zebu bulls. Vet. Med. Int. 2011:43681

Tartaglione, C. M., and M. N. Ritta. 2004. Prognostic value of spermatological parameters as predictors of in vitro fertility of frozenthawed bull semen. Theriogenology 62:1245-1252.

Thundathil, J., J. Gil, A. Januskauskas, B. Larsson, L. Soderquist, R. Mapletoft, and H. Rodríguez-Martínez. 1999. Relationship between the proportion of capacitated spermatozoa present in frozen-thawed semen and fertility with artificial insemination. Int. J. Androl. 22:366-373.

Zini, A., R. Bielecki, D. Phang, and M. T. Zenzes. 2001. Correlations between two markers of sperm DNA integrity, DNA denaturation and DNA fragmentation, in fertile and infertile men. Fertil. Steril. 75:674-677.

Zubkova, E. V., M. Wade, and B. Robaire. 2005. Changes in spermatozoal chromatin packaging and susceptibility to oxidative challenge during aging. Fertil. Steril. 84:1191-1198. 